\title{
PENERAPAN METODE LIFE-CYCLE COST DALAM PERHITUNGAN EVALUASI EKONOMI JEMBATAN UNTUK PENENTUAN PRIORITAS PENANGANAN JEMBATAN
}

\begin{abstract}
APPLICATION OF LIFE-CYCLE COST METHOD IN CALCULATION OF ECONOMIC EVALUATION OF BRIDGES TO DETERMINE THE PRIORITY OF BRIDGE HANDLING
\end{abstract}

\author{
*Risang Aji Dananjoyo \\ Departemen Teknik Sipil dan Lingkungan Universitas Gadjah Mada \\ Akhmad Aminullah \\ Departemen Teknik Sipil dan Lingkungan Universitas Gadjah Mada \\ Email: akhmadaminullah@ugm.ac.id \\ Arief Setiawan Budi Nugroho \\ Departemen Teknik Sipil dan Lingkungan Universitas Gadjah Mada \\ Email: arief_sbn@ugm.ac.id \\ Submitted: 26-10-2018; Revised: 12-02-2019; Accepted: 20-08-2019
}

\begin{abstract}
Bridge oftentimes become a critical component of roads because it used to determine the maximum load capacity of a passing vehicle on the roads. The bridges require maintenance activity in the shape of general maintenance or periodically replacement while this is estimated so that the bridge may continue to function properly. The economic evaluation of the Interurban Bridge Management System (IBMS) aims to determine the priority of bridge handling. One of the calculations required in NPV and IRR calculations used in priority handling is the cost of replacing the bridge. Over time, the Interurban Bridge Management System (IBMS) system must be constantly updated to continue to use by current circumstances and use new, better methods. This study uses the Life-Cycle Cost (LCC) method as an alternative method to calculate the replacement cost of 5 bridges in Daerah Istimewa Yogyakarta in 2012. The IBMS method produces a priority sequence of bridge handling with Bogo bridge, Suru bridge, Winongo bridge, Kalasan B bridge and Duren bridge in sequence. The Life-Cycle Cost (LCC) method produces a priority sequence of bridge handling with Bogo bridge, Winongo bridge, Suru bridge, Kalasan $B$ bridge, and Duren bridge. The average initial cost of bridge replacement using both methods is $23.012 \%$. The value earned using the Life-Cycle Cost method is always greater due to the addition of inspection fees, maintenance costs, and damage costs of the bridge.
\end{abstract}

Keywords: Bridge; IBMS; Life-Cycle Cost; Priority of Bridge Handling.

${ }^{*}$ Corresponding author: risangajidananjoyo@gmail.com

Copyright $\odot 2020$ THE AUTHOR(S). This article is distributed under a Creative Commons Attribution-Share Alike 4.0 International license. Jurnal Teknosains is published by the Graduate School of Universitas Gadjah Mada. 


\begin{abstract}
ABSTRAK
Jembatan merupakan penentu kapasitas beban maksimum kendaraan yang melewati ruas jalan. Jembatan menjadi komponen kritis dari suatu ruas jalan dan jembatan membutuhkan aktivitas pemeliharaan berupa perawatan maupun penggantian secara berkala. Hal ini diperkirakan agar jembatan dapat terus berfungsi dengan baik. Evaluasi ekonomi pada Interurban Bridge Management System (IBMS) bertujuan untuk menentukan prioritas penanganan jembatan. IBMS ini mencakup pemeriksaan, rencana, dan program pemeliharaan jembatan yang telah disusun secara sistematis. Salah satu perhitungan yang dibutuhkan dalam perhitungan NPV dan IRR yang digunakan dalam penentuan prioritas penanganan adalah biaya penggantian jembatan. Seiring dengan berjalannya waktu sistem IBMS harus terus diperbaiki agar dapat terus dipakai sesuai kondisi saat ini serta menggunakan metode-metode baru yang lebih baik lagi. Penelitian ini menggunakan metode Life-Cycle Cost (LCC) sebagai metode alternatif untuk perhitungan biaya penggantian lima jembatan di Daerah Istimewa Yogyakarta pada tahun 2012. Metode IBMS menghasilkan urutan prioritas penanganan jembatan dengan jembatan Bogo, jembatan Suru, jembatan Winongo, jembatan Kalasan B dan jembatan Duren secara berurutan. Metode LCC menghasilkan urutan prioritas penanganan jembatan dengan jembatan Bogo, jembatan Winongo, jembatan Suru, jembatan Kalasan B dan jembatan Duren. Rata-rata dari selisih perhitungan biaya awal penggantian jembatan menggunakan kedua metode adalah $23,012 \%$. Nilai yang didapatkan menggunakan metode Life-Cycle Cost selalu lebih besar karena adanya penambahan biaya inspeksi, biaya perawatan dan biaya kerusakan jembatan.
\end{abstract}

Kata Kunci: IBMS; Jembatan; Life-Cycle Cost; Prioritas Penanganan Jembatan.

\section{PENGANTAR}

Jaringan jalan sebagai salah satu jenis infrastruktur transportasi, pada lokasi tertentu membutuhkan infrastruktur berupa jembatan untuk dihubungkan. Salah satu masalah yang berkaitan dengan infrastruktur jalan raya adalah biaya pemeliharaan jaringan jembatan dengan tingkat layanan yang dapat diterima lebih banyak dari pada dana yang dianggarkan. Jembatan adalah bangunan yang dibuat untuk melintasi rintangan alami maupun rintangan buatan dan juga sebagai penghubung ruas-ruas jalan. Jembatan merupakan penentu kapasitas beban maksimum kendaraan yang melewati ruas jalan, jembatan menjadi komponen kritis dari suatu ruas jalan tersebut. Secara umum perekonomian nasional dan daerah sangat ditentukan kondisi jaringan jalan raya (Triwiyono, 2016).

Jembatan membutuhkan pemeliharaan berupa perawatan maupun penggantian secara berkala, hal ini diperlukan agar jembatan dapat terus berfungsi dengan baik. Kementerian Pekerjaan Umum dan Perumahan Rakyat telah mengembangkan suatu sistem pengelolaan dan pemeliharaan jembatan yang disebut Interurban Bridge Management System (IBMS). IBMS ini mencakup pemeriksaan, rencana, dan program pemeliharaan jembatan yang telah disusun secara sistematis. Pemeriksaan jembatan dapat dipantau dan diatur secara sistematis melalui proses pengumpulan data fisik serta kondisi struktur jembatan dengan menggunakan sistem ini. Selain itu IBMS dapat digunakan untuk menganalisa data serta memberikan alternatif pemeliharaan jembatan berupa pemeliharaan rutin, rehabilitasi, perkuatan, dan penggantian jembatan.

Berdasarkan Panduan Rencana dan Program IBMS (1993), tujuan pokok IBMS antara lain: untuk menghasilkan suatu jaringan jembatan yang aman dan fungsional; untuk mengoptimumkan penggunaan data; untuk menjamin bahwa Ditjen Bina Marga memiliki data yang terbaru, benar, mudah diperoleh, dan berguna untuk semua jembatan yang ada. Direktorat Jenderal Bina Marga dalam buku Panduan Rencana dan Program IBMS menjelaskan salah satu langkah dalam penyusunan draft program (rencana) adalah melakukan evaluasi ekonomi dengan output berupa urutan daftar jembatan untuk program penggantian dan rehabilitasi. Parameterparameter yang digunakan dalam laporanlaporan IBMS dan perhitungan yang digunakan dalam evaluasi ekonomi dan pe-ranking-an proyek-proyek jembatan ini adalah Net Present Value (NPV) dan Internal Rate of Return (IRR) dari harga konstruksi jembatan saja. Pada 
kenyataannya aspek-aspek permasalahan di lapangan lebih kompleks lagi, seperti: biayabiaya perawatan rutin, biaya inspeksi, biaya kerusakan, pertambahan jumlah kendaraan, dan lain-lain.

Menurut Hariman (2007), prioritas penanganan jembatan ditentukan oleh urutan nilai ekonomisnya menggunakan NPV dan IRR sebagai indeks ranking. NPV dan IRR secara otomatis mengurutkan jembatan yang telah dievaluasi secara ekonomi. Jembatan mempunyai prioritas lebih tinggi apabila memiliki nilai keuntungan ekonomi lebih tinggi dibandingkan dengan jembatan dengan nilai keuntungan ekonomi yang lebih rendah. Ketika nilai NPV positif maka keriteria program tersebut dapat direkomendasikan.

Sistem manajemen pemeliharaan aset jalan raya yang melibatkan lebih dari satu aset jalan raya, mengidentifikasi alokasi optimal anggaran yang tersedia untuk sistem aset individual merupakan tantangan utama. Anggaran untuk pemeliharaan harus dikelola dengan cermat agar dapat digunakan secara efisien. Banyak aspek yang perlu dipertimbangkan agar pengelolaan anggaran dapat berjalan dengan efisien. Penelitian ini akan membangun sebuah sistem untuk menentukan prioritas penanganan jembatan dengan menambahkan biaya siklus hidup atau Life-Cycle Cost jembatan yang belum ada pada IBMS pada saat ini.

Total Life-Cycle Cost (LCC) adalah jumlah dari total biaya ekonomis, biaya yang memiliki biaya operasi suatu fasilitas, dan proses manufaktur atau produksi merupakan seluruh biaya parsial tahunan. Nilai biaya sekarang (present value) dan nilai yang akan datang (future value) dari suatu proyek selama umur manfaat proyek itu sendiri digambarkan menggunakan analisis Life-Cycle Cost. Amalia (2014) menggambarkan LCC terdiri dari tahapan inisial, operasional, pemeliharaan, dan perbaikan. Semua parameter yang digunakan dalam analisis LCC jembatan dapat mempengaruhi hasil analisis dan keputusan manajemen jembatan berdasarkan analisis tersebut, tetapi parameter tertentu lebih berpengaruh atau lebih mendasar dengan prinsip- prinsip analisis LCC dan mungkin perlu mendapat perhatian yang lebih besar.

Penelitian sebelumnya yang menggunakan Life-Cycle Cost pada proyek jembatan antara lain, Okasha (2012) menggunakan dua metode analisis, yaitu metode analisis deterministik dan metode analisis probabilistic bahwa membandingkan analisa LCC pada simulasi dua pekerjaan proyek yang sama, tetapi dengan cara yang berbeda. Tujuannya untuk mengetahui cara yang lebih efektif dalam pengerjaan suatu proyek jembatan. Variabel acak yang digunakan untuk mengetahui LCC adalah interval waktu pengecatan ulang dan dihitung menggunakan semua kombinasi jarak pengecatan ulang.

Soliman dan Frangopol (2015) merupakan riset lanjutan dari riset sebelumnya oleh Okasha (2012) dengan menyajikan pendekatan komputasional dan juga hasil dari investigasi analitikal untuk mengukur LCC dari jembatan baja yang dibangun menggunakan painted baja karbon konvensional dan membandingkan biayanya dengan jembatan yang sama yang dibangun menggunakan baja bebas perawatan. LCC dalam riset ini meliputi biaya awal dan biaya perawatan pelapisan cat jembatan. Biaya awal terdiri dari harga material, pabrikasi, pengecatan awal, shop inspection, dan transportasi. Selanjutnya biaya perawatan meliputi: pelapisan cat ulang dan biaya lalu lintas sebagai tambahan naiknya biaya tidak langsung dari tundaan lalu lintas dan dampak sosial serta lingkungan.

Kajian sebelumnya yang menggunakan BMS antara lain, Hariman (2007), penilaian kondisi jembatan dilakukan secara visual menggunakan standar Bridge Management System (BMS) untuk mengetahui kondisi eksisting jembatan secara keseluruhan. Sistem Informasi Bridge Management System (SIM-IBMS) juga digunakan untuk menentukan usulan rencana penanganan serta menyusun daftar peringkat (skala prioritas) jembatan. Mungkasa (2008), menggunakan metode NYSDOT (New York State Department of Transportation) dilengkapi dengan AHP (Analytical Hierarchy Process) untuk melakukan penilaian kondisi jembatan dengan menghitung pembobotan komponen 
jembatan. Komponen jembatan menggunakan beban pembobotan dibagi menjadi tiga kategori, yaitu (1) komponen struktur menerima beban lalu lintas secara langsung (komponen yang mendistribusikan beban lalu lintas) di mana nilai kepentingannya lebih tinggi sebagai prioritas awal, (2) menerima beban tidak langsung dari beban lalu lintas, dan (3) komponen nonstruktur. Komponen-komponen tersebut mengacu pada nilai kepentingan dihitung dan disusun menggunakan matriks "perbandingan berpasangan".

Solahuddin dan Andi (2006) mengatakan di dalam suatu sistem informasi harus ada informasi mengenai gambaran kondisi eksisting jembatan agar pengelola jembatan dapat menetapkan keputusan berdasarkan informasi tersebut. Penilaian kondisi jembatan menggunakan DER rating, yaitu menggunakan konsep pengurangan nilai untuk menilai kerusakan secara visual. Kondisi jembatan yang baik memiliki elemen dan sub-item jembatan bernilai 100, dan kerusakan yang terjadi dianggap sebagai nilai pengurangan. Berdasarkan degree (jenis), extent (luas), dan relevancy (relevansi)nya untuk menilai kerusakan sub-item jembatan tersebut, kemudian dirata-rata dan dikalikan dengan weight factor (bobot faktor) dari tiap elemennya, pada akhirnya condition index jembatan tersebut dapat dihasilkan. Asumsi menggunakan IBMS untuk memberikan informasi penundaan waktu penanganan didapat dari perkiraan waktu layanan jembatan.

Ramanta (2015) menentukan prioritas penganganan berdasarkan bridge condition rating jembatan, sedangkan usulan penanganannya berdasarkan kombinasi nilai kondisi dan nilai lalu lintas jembatan. Informasi waktu penggantian jembatan dan proyeksi nilai kondisi yang digunakan IBMS kemudian dimodifikasi untuk penyesuaian skala penilaian NYSDOT.

Tujuan utama penelitian ini adalah untuk membandingkan hasil perhitungan biaya awal penggantian jembatan menggunakan LCC dengan perhitungan menggunakan IBMS serta membandingkan hasil penentuan prioritas penanganan jembatan menggunakan metode
LCC dengan metode IBMS. Diharapkan nantinya dapat menjadi metode perhitungan alternatif yang lebih mendetail dalam penentuan prioritas penanganan jembatan di Indonesia.

\section{Metode}

Riset ini menggunakan dua metode untuk menghitung biaya awal jembatan, yaitu (1) menggunakan perhitungan cara konvensional IBMS, dan (2) menggunakan perhitungan alternatif dengan Life Cycle Cost. Pada Panduan Rencana dan Program IBMS (1993) yang dikeluarkan oleh Kementerian PU telah dijabarkan bagaimana menghitung nilai ekonomi jembatan menggunakan NPV dan IRR.

\section{Penentuan Base Case}

Capaian Umur Jembatan pada Nilai Kondisi (NK) yang Spesifik. Perkiraan kapan jembatan yang akan dianalisis menjadi rusak berat, kritis, atau bahkan runtuh/tidak berfungsi perlu dilakukan untuk menentukan base case. Suatu jembatan diasumsikan memiliki umur rencana selama $\mathrm{N}$ tahun dan akan mengalami kerusakan mulai dari NK $=0$ - NK $=5$ pada akhir umur rencana UR. Perhitungan dapat dimulai dengan menghitung deterioration model pada jembatan yang akan diskrining untuk menentukan capaian umur jembatan pada NK yang spesifik.

1) Menghitung karakter umur jembatan

$U R=\frac{(\text { Tahun survey }- \text { Tahun pembangunan jembatan }) \times 100}{\left(100-a \times(5-C M)^{b}\right)}$

Keterangan:

a: 4,66

b: 1,905

(Sumber: Panduan Rencana dan Program IBMS, 1993)

2) Hitung lama tahun jembatan tersebut untuk mengetahui NK yang diprediksikan

Capaian Umur Jembatan $=$

$$
\frac{\left(100-a x(5-C M)^{b}\right)}{100} \times U R
$$


Keterangan:

NK : Nilai Kondisi

UR : Umur Rencana

CM : Condition Mark, nilai kondisi pada tahun $y$

(Sumber: Panduan Rencana dan Program IBMS, 1993)

3) Hitung tahun capaian NK jembatan yang diinginkan

Menjumlahkan tahun pembuatan jembatan dan umur capaian jembatan dengan NK yang spesifik.

Base Case berikutnya merupakan tentang biaya, yaitu mencakup dua jenis penghematan penting sebagai berikut:

1) Biaya-biaya lalu lintas (pengalihan arus, pengurangan kecepatan, dan lain sebagainya).

a) Pengalihan Arus; pada base case biaya pengalihan arus lalu lintas yang digunakan berdasarkan pada BOK, biaya (nilai) waktu penumpang tidak dimasukkan dalam perhitungan. Rumus berikut ini dapat menentukan biaya tersebut:

$B P L=L H R T \times B O K \times$ Jarak $x$ Lama

Pengalihan Arus.

Keterangan:

BPL :Biaya Pengalihan Arus

LHRT : Lalu Lintas Harian Rata-Rata (LHR) pada tahun di mana arus dialihkan

BOK :Biaya Operasional Kendaraan per kilometer

Jarak :Tambahan jarak yang ditempuh kendaraan karena adanya penutupan jembatan

(Sumber: Panduan Rencana dan Program IBMS, 1993)

b) Pengurangan Kecepatan; pada waktu kendaraan harus mengurangi kecepatan untuk melintasi jembatan akan menimbulkan biaya ini. Kondisi jembatan yang buruk menimbulkan biaya atas dasar tambahan waktu yang dibutuhkan untuk melintasi jembatan yang rusak tersebut (Panduan Rencana dan Program IBMS, 1993).

$B P K=L H R T \times B O K \times$ Jarak $\times$ Lama

penanganan

Keterangan:

BPK : Biaya Pengurangan

Kecepatan

LHRT : Lalu Lintas Harian RataRata (LHR) pada tahun di mana arus dialihkan

BOK : Biaya Operasional

Kendaraan

Jarak : Panjang jembatan (m)

Lama Penanganan : Dalam

IBMS ditetapkan lama

penanganan 60 hari

(Sumber: Panduan Rencana dan Program IBMS, 1993)

c) Dalam penelitian ini data BOK menggunakan BOK yang telah ditentukan program IBMS yaitu Rp340,469 / km

2) Ketika jembatan mencapai kondisi kritis, maka akan timbul biaya pekerjaan jembatan sebagai berikut:

a) Biaya Rehabilitasi Jembatan; analisis sistem IBMS mengasumsikan bahwa total biaya penggantian jembatan terdiri dari biaya penggantian masing-masing elemen (lihat Tabel 1)

Tabel 1

Persentase Iaya Pada Elemen-Elemen Utama Jembatan

\begin{tabular}{l|l|l}
\hline \multicolumn{1}{c|}{ Elemen } & \% Biaya Jembatan & Umur \\
\hline Daerah Aliran & 3,5 & 50 \\
\hline Tanah Timbunan & 5,6 & 50 \\
\hline $\begin{array}{l}\text { Bangunan } \\
\text { Pengaman }\end{array}$ & 5,6 & 25 \\
\hline Pondasi & 11,3 & 50 \\
\hline Kepala Jembatan & 14,1 & 50 \\
\hline Bangunan Atas & 45,8 & 50 \\
\hline Lantai & 14,1 & 30 \\
\hline Total & 100 & \\
\hline
\end{tabular}

(Sumber: Panduan Rencana dan Program IBMS, 1993) 
b) Biaya Jembatan Sementara: buku Panduan Rencana dan Program IBMS (1993) mencantumkan biaya jembatan sementara yang biasa disebut juga dengan jembatan bely sebesar Rp1juta/meter sehingga dirasa sudah tidak relevan. Rahardjoputro (2015) menghitung harga jembatan bely ini dan didapatkan hasil sebesar Rp24 juta/ meter untuk bentang pendek dan Rp48 juta/meter untuk bentang panjang.

c) Konsep Perhitungan Manfaat

Penghematan yang timbul akibat perbaikanjembatan pada tahun penanganan dapat menghasilkan manfaat (Panduan Rencana dan Program IBMS, 1993). Rahardjoputro (2015) mengatakan bahwa manfaat dapat timbul karena rehabilitasi dan penggantian elemen pada tahun penanganan.

1) Manfaat penggantian jembatan; saat nilai kondisi (NK) jembatan sama dengan lima (kondisi runtuh), biaya penggantian jembatan yang ditarik di waktu kondisi runtuh sama dengan nilai manfaatnya, dengan rumus:

$M P J_{n}=B P J_{0} \times(1+i)^{n}+B_{1}+B_{2}+B_{3}+B_{4}$

Keterangan:

$\mathrm{MPJ}_{\mathrm{n}}$ : Manfaatyang timbul padatahun ke- $n$ akibat perbaikan jembatan pada tahun penanganan

BPJ $_{0}$ : Biaya penggantian jembatan pada tahun penanganan

i : Tingkat potongan untuk evaluasi ekonomi sebesar 15\%

n : Tahun penggantian jembatan

$\mathrm{B}_{1}$ : Biaya pengalihan arus pada tahun ke- $n$

B2 : Biaya jembatan sementara pada tahun ke- $n$

B3 : Biaya pemeliharaan jembatan lama pada tahun ke- $n$ sebesar 0,5\% BPJ0

B1 : Biaya pemeliharaan jembatan baru pada tahun ke- $n$ sebesar $2 \% \mathrm{BPJ}_{0}$

(Sumber: Rahardjoputro, 2015)
2) Manfaat pengurangan kecepatan; rehabilitasi yang dilakukan pada tahun penanganan menyebabkan terjadinya degradasi kondisi jembatan di tahuntahun berikutnya, mengakibatkan tidak terjadi pengurangan kecepatan sehingga dapat menimbulkan manfaat. Berikut ini rumus untuk mendapatkan besarnya nilai manfaat pengurangan kecepatan:

$M P K_{n-1}=\sum_{n=-1}^{N} B O K \times L H R T \times P \times(1+\mathrm{r}) \mathrm{n}-1$

Keterangan:

MPK : Manfaat Pengurangan Kecepatan

BOK : Biaya Operasional Kendaraan

$r \quad$ : Faktor pertumbuhan kendaraan

n : Tahun penggantian jembatan

LHRT : Laju harian rata-rata tahunan

$\mathrm{P}$ : Panjang jembatan

(Sumber: Rahardjoputro, 2015).

a. Evaluasi Ekonomi

Analisis Net Present Value dan Internal Rate of Return digunakan untuk evalusai ekonomi jembatan pada penelitian ini. Seluruh biaya seperti biaya rehab, biaya penggantian elemen, pengurangan kecepatan, dan biaya jembatan sementara yang dijumlahkan hingga mendapatkan total biaya rehabilitasi pada tahun penanganan. Rata-rata biaya penggantian jembatan didapat ketika pengumpulan data telah dikonversikan dengan mengalikan biaya penggantian jembatan tersebut dengan $(1+i)^{n}$ di mana $i$ adalah tingkat potongan untuk evaluasi ekonomi, dan $n$ adalah selisih antara tahun yang akan ditinjau dengan tahun di mana biaya penggantian jembatan yang telah ditambah dengan beberapa base case yang terdiri dari; biaya pengalihan arus setelah jembatan runtuh, biaya jembatan sementara, biaya kehilangan kecepatan pada jembatan sementara, biaya pemeliharaan jembatan lama, dan biaya pemeliharaan jembatan baru.

Proyek rehabilitasi ini dinyatakan layak dilakukan atau tidak melalui perhitungan NPV, yaitu membuat selisih 
dari biaya kedua program penanganan. Total biaya rehabilitasi yang akan dilaksanakan pada tahun survei dibandingkandengan biaya penggantian jembatan di tahun runtuhnya jembatan tersebut serta adanya penambahan biaya penurunan kecepatan dari tahun ke tahun disebabkan oleh jembatan yang kondisinya semakin memburuk, sehingga pada akhirnya jembatan tersebut diganti atau runtuh. Jembatan tersebut tidak layak untuk diprioritaskan dalam program penanganan rehabilitasi apabila selisih biaya dari kedua program tersebut negatif (-), tetapi apabila selisih biayanya positif $(+)$ maka jembatan tersebut layak untuk mendapatkan prioritas penanganan rehabilitasi. Semakin besar selisih biaya rahabilitasi jembatan tersebut, maka pe-ranking-an program penanganan rehabilitasi akan semakin tinggi.

Proyek tersebut dapat dinyatakan ekonomis atau tidak melalui perhitungan IRR. Untuk mencari IRR saat itu, IRR di-nol-kan agar proyek tersebut berada dalam ambang tidak merugi dan tidak untung. Berdasarkan kebijakan yang tertera pada Panduan Rencana dan Program IBMS, proyek tersebut dapat dinyatakan ekonomis apabila besaran IRR $>15 \%$, tetapi apabila besaran IRR tersebut $\leq 15 \%$ maka proyek tersebut dinyatakan tidak ekonomis, walaupun memiliki nilai NPV positif yang berarti layak untuk dilaksanakan.

b. Prioritas Penanganan

Prioritas penanganan jembatan menurut nilai ekonomisnya ditentukan menggunakan NPV dan IRR sebagai indeks ranking. Berdasarkan NPV/m untuk penggantian jembatan dan IRR untuk rehabilitasi, jembatan-jembatan yang telah dievaluasi secara ekonomis akan diurutkan secara otomatis. Jembatan-jembatan mempunyai prioritas yang lebih utama apabila memiliki nilai keuntungan ekonomi lebih tinggi dibandingkan dengan jembatan-jembatan dengan nilai keuntungan ekonomi yang lebih rendah. Urutan prioritas jembatanjembatan tersebut kemudian dialokasikan ke dalam program indikatif dan dipotong hingga anggaran yang dialokasikan habis terpakai.

Menurut Amalia (2014) pengkategorian biaya siklus hidup akan dihitung dengan dibagi menjadi empat kategori biaya sebagai berikut:

a. Biaya awal (Initial cost)

Henry Simamora (2002) dalam Amalia (2014) menyatakan biaya awal (initial cost) pada analisis Life Cycle Cost jembatan ini dapat diperoleh dari harga satuan luas penggantian jembatan yang disesuaikan dengan luas lantai jembatan.

$I C=P \times L \times H L P$

Keterangan :

IC : Initial Cost (biaya awal)

$\mathrm{P}$ : Panjang jembatan

L : Lebar jembatan

HLP : Harga satuan luas penggantian jembatan

(Sumber: Amalia, 2014)

b. Biaya perawatan rutin

Menurut Amalia (2014) biaya perawatan (maintenance cost) dari jembatan dengan struktur beton bertulang yaitu 0,05\% dari biaya awal (initial cost). Perawatan rutin setiap jembatan dilakukan pada setiap tahunnya.

$$
M C=0,05 \% \times I C
$$

Keterangan:

MC : Maintenance Cost (biaya perawatan)

IC : Initial Cost (biaya awal).

(Sumber: Amalia, 2014)

c. Biaya pemeriksaan

Menurut Amalia (2014) biaya pemeriksaan (inspection cost) dari jembatan yaitu 0,15\% dari biaya awal (initial cost). Pemeriksaan jembatan dilakukan setiap 5 tahun.

$I p C=0,15 \% \times I C$ 
Keterangan:

IpC : Inspection Cost (biaya pemeriksaan) IC : Initial Cost (biaya awal).

(Sumber: Amalia, 2014)

d. Biaya Pengguna (User Cost)

1) Biaya Penundaan Perjalanan (Driver Delay Cost), dihitung menggunakan rumus berikut:

$$
D D C=\left(\frac{L}{S a}-\frac{L}{S n}\right) \times A D T \times N \times w
$$

Keterangan:

L : Panjang jalan yang terkena dampak $(\mathrm{km})$

Sa : Kecepatan lalu lintas saat kegiatan perbaikan $(\mathrm{km} / \mathrm{jam})$

$\mathrm{Sn}$ : Kecepatan lalu lintas normal $(\mathrm{km} /$ jam)

ADT : Lalu lintas harian rerata (kendaraan/hari)

$\mathrm{N}$ : Jumlah hari selama perbaikan

W : Nilai waktu pengemudi perjam

(Sumber: Amalia, 2014)

2) Biaya Operasi Kendaraan (Vehicle Operating Cost), dihitung menggunakan rumus:

$V O C=\left(\frac{L}{S a}-\frac{L}{S n}\right) \times A D T \times N \times r$

Keterangan:

L : Panjang jalan yang terkena dampak (km)

Sa : Kecepatan lalu lintas saat kegiatan perbaikan $(\mathrm{km} / \mathrm{jam})$

Sn : Kecepatan lalu lintas normal $(\mathrm{km} / \mathrm{jam})$

ADT: Lalu lintas harian rerata (kendaraan/hari)

$\mathrm{N}$ : Jumlah hari selama perbaikan

$r$ : Biaya operasional kendaraan satuan rata-rata

(Sumber: Amalia, 2014)
3) Tingkat Pertumbuhan Lalu lintas, dihitung menggunakan rumus:

$A A D T_{t}=A A D T \times\left(1+r_{T G}\right)^{\text {Yeart-Yearo }}$

Keterangan:

$\mathrm{AADT}_{t}$ : AADT yang digunakan untuk analisa pada tahun $\mathrm{t}$ (kendaraan/hari)

AADT : Lalu lintas harian rerata (kendaraan/hari)

$\mathrm{r}_{\mathrm{TG}}$ : Perkiraan tingkat pertumbuhan lalu lintas

Year $_{t}$ : Tahun di mana AADT akan dihitung

Year $_{0}$ : Tahun di mana AADT diukur (Sumber: Amalia, 2014)

e. Biaya Perbaikan Masa Depan (Future Rehabilitation Cost)

1) Biaya Perbaikan Elemen 1

$B P_{1}=14,1 \% \times$ Biaya total penggantian jembatan

2) Biaya Perbaikan Elemen 2

$B P_{2}=5,6 \% \times$ Biaya total penggantian jembatan

3) Biaya Perbaikan Elemen 3

$B P_{3}=45,8 \% \times$ Biaya total penggantian jembatan

4) Biaya Perbaikan Elemen 4 $B P_{4}=14,1 \% \times$ Biaya total penggantian jembatan $+R p .100 .000 .000,00$

(Sumber: Amalia, 2014)

Pembandingan akan dilakukan terhadap dua hasil analisis menggunakan hasil NPV dan IRR dengan tingkat potongan 15\%, dan ditentukan ranking jembatan yang lebih layak dan ekonomis untuk diperbaiki.

\section{HASIL DAN PEMBAHASAN}

Perbandingan hasil analisis menggunakan kedua metode pada jembatan Winongo dapat diringkas seperti yang ditunjukkan pada Tabel 2. 
Tabel 2

Perbandingan hasil perhitungan dengan metode IBMS dan Life-Cycle Cost

\begin{tabular}{l|l|l}
\multicolumn{1}{c|}{ Jembatan Winongo } & \multicolumn{1}{c}{ IBMS } & \multicolumn{1}{c}{ LCC } \\
\hline Total Biaya Penggantian Jembatan & $\operatorname{Rp~11.996.864.231,97}$ & $\operatorname{Rp~15.782.227.016,31}$ \\
\hline NPV & $\operatorname{Rp~5.217.480.040,45~}$ & $\operatorname{Rp~7.381.773.498,14}$ \\
\hline NPV / m & $\operatorname{Rp~165.110.127,86~}$ & $\operatorname{Rp~233.600.427,16}$ \\
\hline IRR & $64,414 \%$ & $76,082 \%$ \\
\hline
\end{tabular}

Berdasarkan hasil penghitungan pada tabel di atas, biaya penggantian jembatan yang dihitung menggunakan metode LCC lebih besar dibandingkan dengan metode IBMS. Hasil nilai NPV, NPV/m, dan IRR juga menjadi lebih besar atau bertambah. Hal ini

terjadi karena adanya penambahan biaya siklus hidup jembatan yang sebelumnya belum ada pada metode IBMS. Penghitungan LCC yang merupakan penghitungan alternatif ini dapat digunakan untuk menghasilkan hitungan yang lebih mendetail dalam prioritas penanganan jembatan di Indonesia.

Tabel 3

Perbandingan hasil perhitungan total biaya penggantian jembatan

\begin{tabular}{l|l|l}
\hline \multirow{2}{*}{\multicolumn{1}{c}{ Jembatan }} & \multicolumn{2}{|c}{ Total Biaya Penggantian Jembatan } \\
\cline { 2 - 3 } & \multicolumn{1}{|c}{ IBMS } & \multicolumn{1}{c}{ LCC } \\
\hline Bogo & $\operatorname{Rp~10.774.309.599,26~}$ & $\operatorname{Rp~13.950.880.198,23}$ \\
\hline Duren & $\operatorname{Rp~} 891.651 .146 .799,39$ & $\operatorname{Rp~928.677.392.585,52}$ \\
\hline Kalasan B & $\operatorname{Rp~12.475.975.761,35~}$ & $\operatorname{Rp~17.136.448.233,12~}$ \\
\hline Suru & $\operatorname{Rp~49.650.221.789,33~}$ & $\operatorname{Rp~55.864.709.865,61}$ \\
\hline Winongo & $\operatorname{Rp~11.996.864.231,97}$ & $\operatorname{Rp~15.782.227.016,31}$ \\
\hline
\end{tabular}

Sumber: Olah Data Pribadi Penulis

Tabel 3 menunjukkan perbandingan total biaya awal jembatan antara perhitungan menggunakan metode IBMS dengan metode Life-Cycle Cost. Perbedaan pada hasil perhitungan tersebut terjadi akibat tambahan biaya inspeksi dan perawatan jembatan yang diperhitungkan dalam metode LifeCycle Cost. Rata-rata dari selisih perhitungan menggunakan kedua metode adalah 23,012\%.

Tabel 4

Perbandingan hasil NPV pe-ranking-an jembatan

\begin{tabular}{l|l|l|l}
\hline \multicolumn{1}{c|}{ Jembatan } & \multicolumn{1}{c|}{ IBMS } & \multicolumn{1}{c}{ Jembatan } & \multicolumn{1}{c}{ LCC } \\
\hline Winongo & $\operatorname{Rp~5.217.480.040,45}$ & Winongo & $\operatorname{Rp~7.381.773.498,14~}$ \\
\hline Suru & $\operatorname{Rp~2.596.151.445,63}$ & Bogo & $\operatorname{Rp~3.101.922.093,15~}$ \\
\hline Bogo & $\operatorname{Rp~2.316.722.423,17~}$ & Suru & $\operatorname{Rp~2.975.858.400,56~}$ \\
\hline Kalasan B & $\operatorname{Rp~204.381.056,75}$ & Kalasan B & $\operatorname{Rp~531.850.649,97~}$ \\
\hline Duren & $-\operatorname{Rp~563.273.932,26~}$ & Duren & $-\operatorname{Rp~556.887.716,64~}$ \\
\hline
\end{tabular}

Sumber: Olah Data Pribadi Penulis 
Tabel 4 menunjukkan hasil perhitungan NPV, yaitu perbedaan selisih total biaya rehabilitasi pada metode IBMS dan LCC yang akan dilaksanakan pada tahun survei dibandingkan dengan biaya penggantian jembatan di tahun runtuhnya jembatan tersebut serta adanya penambahan biaya penurunan kecepatan dari tahun ke tahun karena jembatan yang semakin memburuk kondisinya hingga akhirnya jembatan tersebut diganti atau runtuh. NPV Jembatan Duren pada kedua metode tersebut menunjukkan nilai negatif (-), maka dapat dipastikan bahwa Jembatan Duren tersebut tidak layak untuk diprioritaskan dalam program penanganan rehabilitasi. Semakin besar selisih biaya tersebut maka peranking-an program penanganan rehabilitasi akan semakin tinggi.

Tabel 5

Perbandingan hasil NPV / m pe-ranking-an jembatan

\begin{tabular}{l|l|l|l}
\multicolumn{1}{c|}{ Jembatan } & \multicolumn{1}{c|}{ IBMS } & \multicolumn{1}{c}{ Jembatan } & \multicolumn{1}{c}{ LCC } \\
\hline Bogo & $\operatorname{Rp~214.511.335,48}$ & Bogo & $\operatorname{Rp~287.215.008,63~}$ \\
\hline Suru & $\operatorname{Rp~185.439.388,97}$ & Winongo & $\operatorname{Rp~233.600.427,16~}$ \\
\hline Winongo & $\operatorname{Rp~165.110.127,86}$ & Suru & $\operatorname{Rp~212.561.314,33~}$ \\
\hline Kalasan B & $\operatorname{Rp~13.446.122,15}$ & Kalasan B & $\operatorname{Rp~34.990.174,34~}$ \\
\hline Duren & $-\operatorname{Rp} 26.569 .525,11$ & Duren & - Rp 26.268.288,52 \\
\hline
\end{tabular}

Sumber: Olah Data Pribadi Penulis

Perbedaan penentuan ranking prioritas penanganan dapat dilihat pada Tabel 5. Kedua metode sama-sama memberikan urutan pertama untuk Jembatan Bogo, untuk urutan ke-dua metode IBMS memberikan prioritas penanganan kepada Jembatan Suru sedangkan metode Life-Cycle Cost kepada Jembatan Winongo. Urutan berikutnya (empat dan lima) memberikan hasil sama, yaitu Jembatan Kalasan B dan Jembatan Duren secara berurutan. Perbedaan urutan terjadi karena perhitungan menggunakan metode Life-Cycle Cost lebih memperhatikan Nilai Kondisi (NK) jembatan. Dari data sebelumnya, Jembatan Bogo memiliki NK lebih tinggi dari Jembatan Suru yang berarti kondisinya lebih buruk. Kedua metode sama-sama memiliki nilai negatif (-) pada penghitungan NPV/m pada jembatan Duren. Berdasarkan pada analisis menggunakan kedua metode (Tabel 5), berarti proyek perbaikan untuk Jembatan Duren tidak layak untuk dilakukan. Hal ini disebabkan jembatan memiliki NK yang rendah atau berarti jembatan ada dalam kondisi baik.
Tabel 6

Perbandingan hasil peringkat IRR jembatan

\begin{tabular}{l|l|l}
\hline \multirow{2}{*}{ Jembatan } & \multicolumn{2}{|c}{ IRR } \\
\cline { 2 - 3 } & \multicolumn{1}{|c}{ IBMS } & \multicolumn{1}{c}{ LCC } \\
\hline Winongo & $64,414 \%$ & $76,082 \%$ \\
\hline Bogo & $41,015 \%$ & $44,706 \%$ \\
\hline Suru & $26,692 \%$ & $27,441 \%$ \\
\hline Kalasan B & $16,618 \%$ & $18,583 \%$ \\
\hline Duren & $12,179 \%$ & $12,25 \%$ \\
\hline
\end{tabular}

Sumber: Olah Data Pribadi Penulis

Jembatan dikatakan ekonomis untuk dilakukan penanganan ketika IRR lebih besar 15\%. Prioritas penanganan jembatan ditentukan dengan pe-ranking-an IRR pada jembatan yang diteliti. Jembatan dengan IRR terbesar menjadi prioritas utama penanganan. Berdasarkan pada (Tabel 6), hasil perhitungan menggunakan kedua metode tidak terlihat jauh beda, jembatan dengan nilai ekonomis tertinggi adalah Jembatan Winongo, sedangkan Jembatan Duren dengan presentase $<15 \%$ menjadi sangat tidak ekonomis untuk dilakukan penanganan. 


\section{SIMPULAN}

Rata-rata dari selisih perhitungan biaya awal penggantian jembatan menggunakan kedua metode adalah 23,012\%. Nilai yang didapatkan menggunakan metode LifeCycle Cost selalu lebih besar karena adanya penambahan biaya inspeksi, biaya perawatan, dan biaya kerusakan jembatan. Kedua metode memberikan hasil yang sama, yaitu pertama untuk Jembatan Bogo, kedua metode IBMS memberikan prioritas penanganan kepada Jembatan Suru, ketiga, metode Life-Cycle Cost kepada Jembatan Winongo. Untuk urutan keempat dan kelima dua metode ini memberikan hasil yang sama yaitu Jembatan Kalasan B dan Jembatan Duren secara berurutan. Perbedaan prioritas ini dikarenakan metode Life-Cycle Cost lebih memperhatikan Nilai Kondisi (NK) jembatan. Jembatan yang memiliki NK lebih tinggi atau mengalami kerusakan yang lebih parah mendapat prioritas yang lebih tinggi dari jembatan yang memiliki NK lebih rendah. Jembatan Winongo yang memiliki $\mathrm{NK}=3$ mendapat prioritas lebih tinggi dari pada jembatan Suru, pada peranking-an menggunakan IBMS Jembatan Suru mendapatkan prioritas yang lebih tinggi.

Implikasi dan rekomendasi bahwa Metode perhitungan menggunakan IBMS dapat dikembangkan lebih jauh lagi, dengan cara menambahkan variabel-variabel beserta metode perhitungan yang lebih baik. Jumlah subjek penelitian yang lebih besar dan real akan memperlihatkan kebenaran akan kesimpulan yang dibuat. Parameter-parameter dalam IBMS masih menggunakan estimasi pada tahun IBMS itu dibuat, dibutuhkan penelitian lanjutan untuk menentukan nilai sekarang untuk parameter-parameter tersebut.

\section{DAFTAR PUSTAKA}

Amalia, G. R. (2014). Analisis Biaya Siklus Hidup Jembatan Gelagar Beton Bertulang Konvensional dan Jembatan Inteegral Penuh Beton Bertulang Bentang 20 Meter. (Associate Final Paper), Universitas Gadjah Mada, Yogyakarta. Retrieved from http:// etd.repository.ugm.ac.id/index. php? $\bmod =$ penelitian_detail\&sub $=\mathrm{P}$ enelitianDetail\&act $=$ view \&ty $=$ htm 1\&buku_id=73546\&obyek_id=4

Hariman, F. (2007). Evaluasi dan Program Jembatan Dengan Metode Bridge Management System (BMS): Studi kasus empat jembatan Propinsi D. I. Yogyakarta. (Master Thesis), Universitas Gadjah Mada, Yogyakarta. Retrieved from http:/ / etd.repository.ugm.ac.id/index.php?mod=penelitian_detail\&su $\mathrm{b}=$ PenelitianDetail\&act=view\&typ= html\&buku_id=34165\&obyek_id=4 (c.1 (2226-H-2007))

Indonesia, D. J. B. M. D. P. U. R. (1993). Sistem Manajemen Jembatan. Jakarta: SMEC Kinhill Joint Venture

Indonesia, P. R. (2004). Undang-undang Republik Indonesia nomor 38 Tahun 2004 Tentang Jalan. Jakarta: Kementrian Hukum dan Hak Asasi Manusia

Ministry of Public Works, D. G. o. H., Directorate of Planning. (2012). Bridge Management System Project. Jakarta

Mungkasa, M. (2008). Penilaian Kondisi Jembatan Dengan Metode NYSDOT : Studi kasus 3 jembatan di Kota Kendari. (Master Thesis), Universitas Gadjah Mada, Yogyakarta. Retrieved from http:/ / etd.repository.ugm.ac.id/index.php?mod=penelitian_detail\&su $\mathrm{b}=$ PenelitianDetail\&act=view\&typ= html\&buku_id=40035\&obyek_id=4 (c.1 (3795-H-2008))

Okasha, N. M., Frangopol, D. M., Fletcher, F. B., \& Wilson, A. D. (2012). Life-Cycle Cost Analysis of a New Steel for Bridges. Journal of Bridge Engineering, 17(1), 4. doi:10.1061/(ASCE)BE.19435592.0000219

Rahardjoputro, A. (2015). Sistem Informasi Manajemen Jembatan (SIMJ) Berbasis Web Berdasarkan Evaluasi Ekonomi Sebagai Pendukung Prioritas Penanganan Jembatan. (Master Thesis), Universitas Gadjah Mada, Yogyakarta. Retrieved from http:// 
etd.repository.ugm.ac.id/index. php?mod=penelitian_detail\&sub=P enelitianDetail\&act $=$ view \&ty $\mathrm{p}=\mathrm{htm}$ $1 \& b u k u \_i d=81034 \&$ obyek_id=4

Ramanta, A. (2015). Pengembangan Sistem Informasi Manajemen Jembatan (SIMJ) Berbasis Web Berdasarkan Bridge Condition Rating : Studi kasus 25 jembatan di Lintas Tengah Sumatera Selatan. (Master Thesis), Universitas Gadjah Mada, Yogyakarta. Retrieved from http:/ / etd.repository.ugm.ac.id/index.php?mod=penelitian_detail\&su $\mathrm{b}=$ PenelitianDetail\&act $=$ view $\&$ typ $=$ html\&buku_id=81036\&obyek_id=4

Solahuddin, \& Andi, A. (2007). Pengelolaan Prasarana Jembatan Melalui Sistem Informasi Jembatan : Studi kasus penge- lolaan jembatan di Kabupaten Sragen. (Master Thesis), Universitas Gadjah Mada, Yogyakarta. Retrieved from http:/ / etd.repository.ugm.ac.id/index.php?mod=penelitian_detail\&su $\mathrm{b}=$ PenelitianDetail\&act $=$ view $\&$ typ $=$ html\&buku_id=33298\&obyek_id=4 (c.1 (1370-H-2007))

Soliman, M., \& Frangopol, D. M. (2015). LifeCycle Cost Evaluation of Conventional and Corrosion-Resistant Steel for Bridges. Journal of Bridge Engineering, 20(1), 5. doi:10.1061/(ASCE) BE.19435592.0000647

Triwiyono, A. (2016). Sistem Manajemen Jembatan. Bahan Ajar Magister Pengelolaan Sarana Prasarana. Departemen Teknik Sipil dan Lingkungan. Universitas Gadjah Mada. 